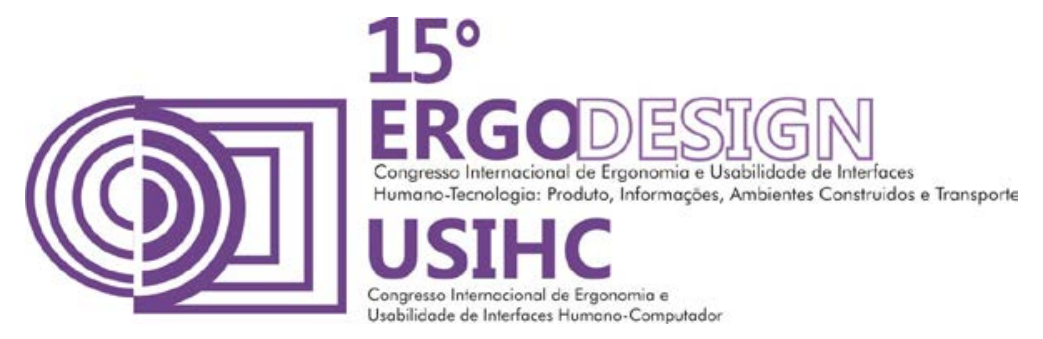

\title{
AVALIAÇÃO ERGONÔMICA DO POSTO DE TRABALHO DO OPERADOR DE MÁQUINA INJETORA: O DESIGN COMO SOLUÇÃO
}

\section{ERGONOMIC EVALUATION ON WORKSTATION OF THE INJECTING MACHINE OPERATOR: DESIGN AS SOLUTION}

\author{
TAVARES, Ademario Santos (1); \\ ALBUQUERQUE, Luiz Wilson Nunes de (2) \\ SOUZA, André Francisco da Silva (3) \\ SOARES, Marcelo Márcio (4) \\ VILLAROUCO, Vilma (5)
}

(1) Universidade Federal de Pernambuco, Mestre em Design e-mail: ademariojr@hotmail.com

(2) Universidade Federal de Pernambuco, Especialista em Ergonomia e-mail: ctiwilson@gmail.com

(3) Universidade Federal de Pernambuco, Especialista em Ergonomia e-mail: andre souzaf@yahoo.com.br

(4) Universidade Federal de Pernambuco, Ph.D. em Ergonomia e-mail: marcelo2@nlink.com.br

(5) Universidade Federal de Pernambuco, Pós-Doutora em Engenharia e-mail:villarouco@hotmail.com

\begin{abstract}
RESUMO
A industrialização e mecanização trouxeram consigo além da otimização do processo produtivo, prejuízos relacionados à saúde e qualidade de vida dos operários. Neste cenário surgiu a Ergonomia como elemento transformador, integralizador e adaptador do processo produtivo, com foco no ser humano, respeitando suas condições físicas e cognitivas. Este trabalho apresenta a aplicação da metodologia de intervenção ergonomizadora em um posto de trabalho de uma indústria de transformação de termoplásticos. Utilizando a metodologia de abordagem sistêmica do SHTM, foram evidenciadas as características organizacionais, físicas, cognitivas e ambientais do posto de trabalho. Foram geradas recomendações e modificações no processo produtivo.
\end{abstract}

Palavras-chave: Ergonomia na indústria, Processo produtivo, Design industrial, Projeto ergonômico

\section{ABSTRACT}

The industrialization and mechanization brought the optimization of the production process, but also 


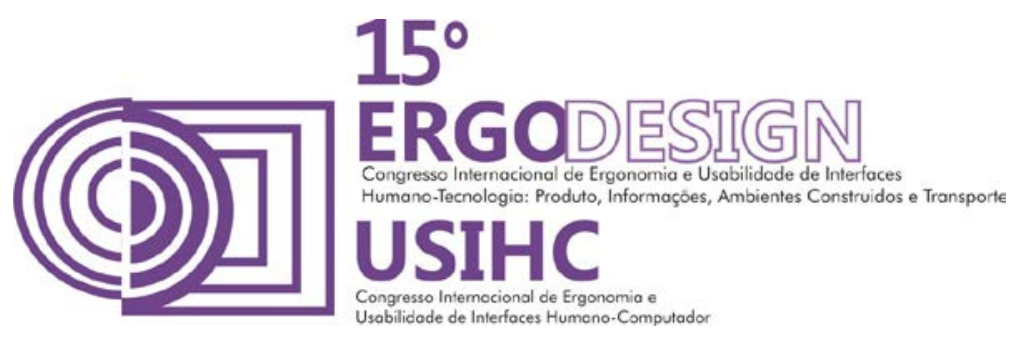

losses related to health and quality of life of workers. In this scenario came Ergonomics as a transforming and adapter element of the production process, focusing on the human being, respecting their physical and cognitive conditions. This paper presents the application of ergonomizadora intervention methodology in a job of a processing thermoplastics industry. Using the systems approach methodology of HumanTask-Machine System were evidenced organizational, physical, cognitive and environmental characteristics of the job. Recommendations and changes were generated in the production process.

Keywords: Ergonomics in the industry, production process, industrial design, ergonomic design

\section{INTRODUÇÃO}

Ao longo dos séculos que sucederam a Revolução Industrial inglesa, os métodos de produção se desenvolveram em proporções enormes. Esta inovação tecnológica possibilitou um crescimento tanto produtivo quanto financeiro, além do surgimento e adaptações de diversas áreas de atuação no processo fabril, a substituição gradual do homem pela máquina, a divisão do trabalho em especialidades, o desenvolvimento dos sistemas de produção, as inovações tecnológicas e a descoberta de novos materiais.

O investimento e o treinamento passam a ser fundamentais para uma empresa sobreviver ao mercado tão concorrido. De acordo com Lucena et. al. (2007), se a produção for bem equipada e gerenciada, a produção pode ser uma excelente arma competitiva. E complementa dizendo que a chave para este gerenciamento é o desenvolvimento de uma estratégia de produção.

Porém a mecanização trouxe consigo a fragmentação das etapas de produção. O conteúdo do trabalho tornou-se rotineiro e monótono. Ao contrário da atividade de artesão, que antigamente participava de toda a produção, a mecanização causou a perda do sentido do trabalho, parcelamento na tarefa e um aumento no ritmo de produção (GUIMARÃES, 2013). O operário passou a executar uma única função, geralmente repetitiva, muitas vezes assumindo poucas ou até mesmo uma única postura durante a jornada diária de trabalho. Neste sentido, os constrangimentos e demais problemas físicos e cognitivos passaram a surgir com maior frequência e intensidade, influenciando negativamente o rendimento dos trabalhadores.

Torna-se necessário um estudo da tarefa executada, de forma a auxiliar os operários na execução de suas atividades com menos riscos de acidentes e danos a sua saúde, e lhe proporcionar mais conforto e bem estar. Entra nessa discussão a ergonomia, suas teorias, princípios e métodos que permitem a otimização do bem estar humano e o desempenho global do sistema (ABERGO, 2013). A abordagem multidisciplinar da ergonomia permite uma aproximação relevante, construtiva e complementar com a atividade humana no trabalho.

Aperfeiçoar o sistema produtivo em uma indústria requer tanto dar ênfase a relação do homem com seu trabalho quanto compreender seus equipamentos e ambientes, lembrando que estes são inerentes ao próprio ser humano (IIDA, 2005, p.36). Diante do exposto, este trabalho busca evidenciar um estudo ergonômico realizado numa indústria de displays de plástico, referenciando o posto de trabalho do operador de máquina injetora. A intervenção ergonomizadora realizada utilizou como base a metodologia de abordagem sistêmica do Sistema Humano-Tarefa-Máquina, proposto por Moraes \& Mont'Alvão (2010). 


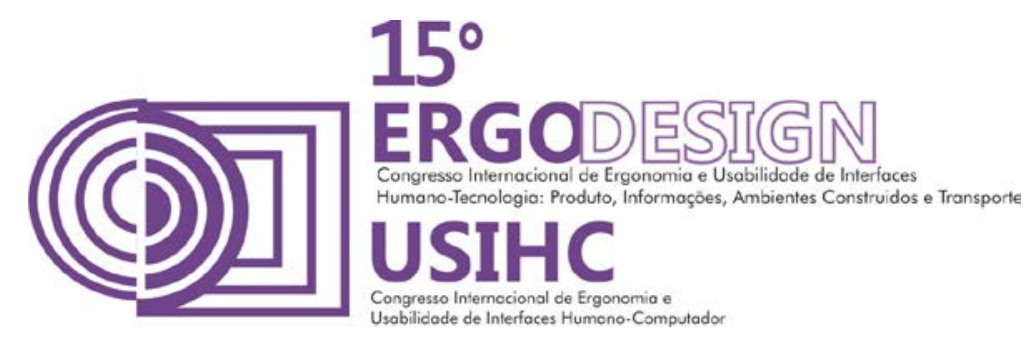

\section{O TRABALHO E SEUS DIVERSOS ASPECTOS}

A condição de trabalho é definida por Leplat e Cuny (1977) como sendo um conjunto de fatores que determinam o comportamento do trabalhador e correspondem as exigências impostas, tais como as condições de execução. Para que o trabalho possa ocorrer é importante que o trabalhador e a empresa estejam em sintonia no que se refere a organização, objetividade, produtividade, segurança, e qualidade de vida. De acordo com Muchinsky (2004, p.239), as organizações são na realidade entidades abstratas, são coletividades de partes que necessitam estar operando coletivamente para alcançarem seus objetivos. Torna-se fundamental conhecer o processo produtivo, afinal, classificar os sistemas de produção é importante para que se estabeleçam relações entre características e possam ser definidas estratégias, incluindo a relação com o trabalhador.

\subsection{Aspectos Organizacionais do Trabalho}

A motivação tornou-se um fator fundamental no mundo da administração e das organizações, proporcionando uma condição física e psicológica importante e indispensável. As motivações surgem sobre os mais diversos motivos como almejar um cargo mais alto ou buscar um aumento de salário ou comissão. A estruturação das organizações permite que o operador tenha um ambiente propício a produção com motivação, devido aos inter-relacionamentos existentes (MUNCHINSKY, 2004).

No caso de um ambiente de trabalho, aspectos como a adaptabilidade e conformidade dos espaços, conforto ambiental e o trabalho ou tarefa que deverá ser desenvolvida são investigados na busca por melhorias relacionadas à segurança, conforto, autonomia e usabilidade. O estudo do ambiente construído enfatiza o local e oposto de trabalho onde são realizadas as atividades, enfatizando o ser humano, suas necessidades, anseios e desejos.

\subsection{Ergonomia e sua muldisciplinaridade}

Neste cenário entra a ergonomia, que de acordo com Pasqualini (2010, p.54), pode ser descrita como um conjunto de ciências e tecnologias que procura a adaptação confortável e produtiva entre o ser humano e seu trabalho, com o intuito de adaptar as condições de trabalho às características do ser humano, buscando o conforto, e a segurança. Soares (2009) enfatiza a abrangência de estudos da ergonomia na indústria quando cita que os requisitos ergonômicos de projeto alcançam desde os produtos e estações de trabalho, até os elementos de comunicação visual e sistemas de informação, incluindo também os sistemas gerenciais e projeto de software. Observa-se aí uma reunião de conhecimentos interdisciplinares focando seus estudos no trabalho. Havendo harmonia entre as condições do ambiente de trabalho; das máquinas, equipamentos e ferramentas; do ser humano; e do processo produtivo, monta-se um cenário ideal para a realização de tarefas com eficiência, segurança, e conforto.

\subsubsection{Ergonomia na indústria}

De acordo com Couto (2011, p.36-37), dentre as metas finais da ergonomia está a busca por reduzir significativamente as lesões e doenças relacionadas ao trabalho, bem como reduzir os acidentes que venham a ser ocasionados por atos e condições inadequadas. Também faz parte 


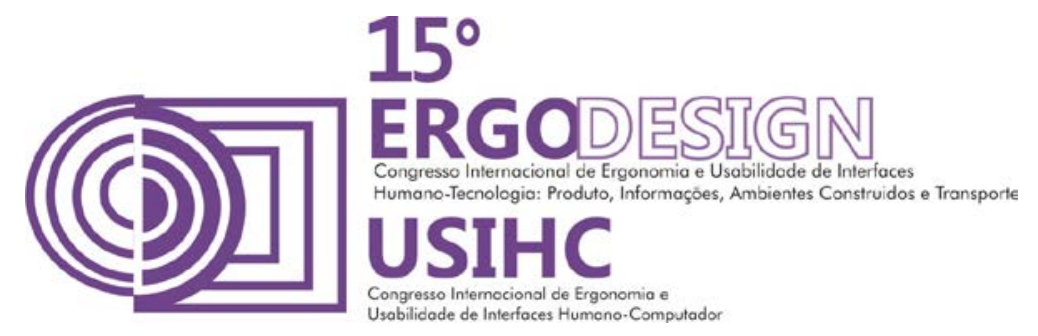

dessa meta conseguir de modo gradativo a eliminação das situações que possam causar desconforto, fadiga, dor e dificuldade na realização do trabalho.

Considerado como a menor unidade produtiva, o posto de trabalho envolve o homem, seu local e toda ajuda material que o indivíduo necessita, tais como máquinas, ferramentas, equipamentos, mobiliário, softwares, sistemas de proteção e segurança, EPIs e o próprio sistema de produção (PASQUALINI, 2010, p. 57). O autor ainda afirma que o posto de trabalho deve estar ergonomicamente adequado ao operador para que possa realizar suas tarefas com conforto, eficiência e eficácia, sem causar dados à saúde física, psíquica e mental.

\section{METODOLOGIA}

A presente pesquisa foi do tipo exploratória, descrevendo as características do fenômeno estudado. A natureza dos dados é qualitativa em alguns momentos e quantitativa em outros. Também é considerada descritiva, pois procurou analisar a frequência de ocorrência de um fenômeno, sem haver manipulação, tendo por objetivo estudar as características de um grupo, ou seja, os operadores de máquina injetora. A amostra desta pesquisa é intencional, pois se trata de um estudo de caso. (LAKATOS, 2003, p.168; GIL, 2008, p.28).

\section{4. $\quad$ ESTUDO DE CASO - INDÚSTRIA DE DISPLAYS}

A empresa localiza-se na Região Metropolitana do Recife, em Jaboatão dos Guararapes, em Pernambuco. Trata-se de uma empresa que desenvolve produtos plásticos (polímeros) para toda região Nordeste. O objeto de estudo é um posto de trabalho do setor de transformação de matéria-prima em produto finalizado.

\subsection{Apreciação Ergonômica}

Por motivos de privacidade, dados sobre a organização da empresa serão mantidos em sigilo e algumas etapas da apreciação ergonômica não serão mencionados, por questões de espaço disponível. No entanto, alguns dados podem ser citados, a título de complemento. A Figura 1 abaixo mostra a localização do posto de trabalho e sua posição no setor de produção.
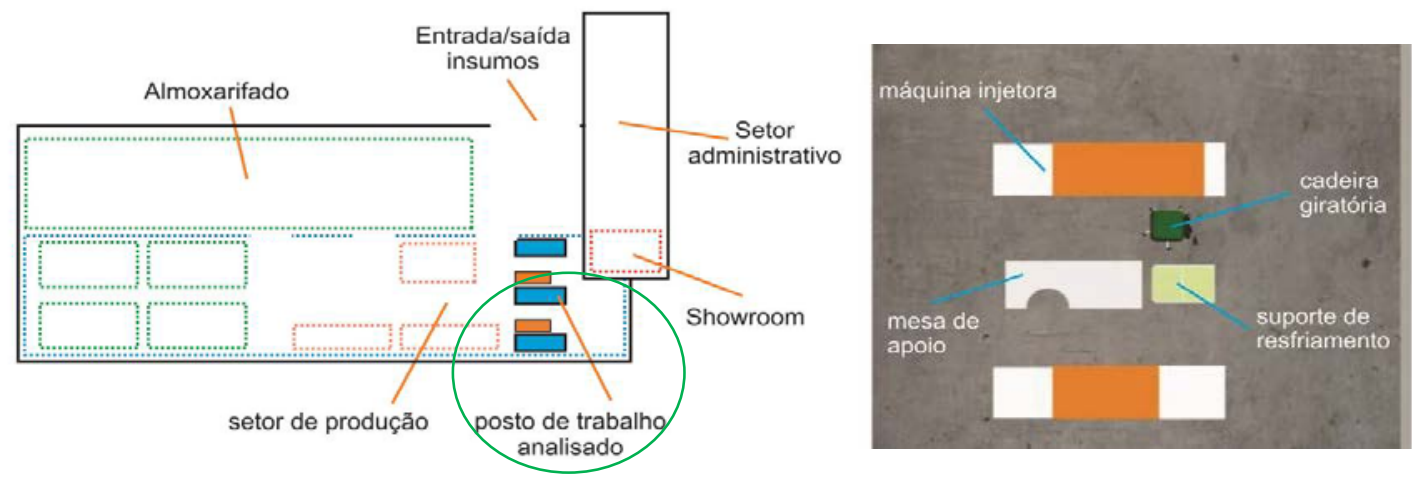

Figura 1. Croqui esquemático da indústria ICD e detalhes do posto de trabalho 


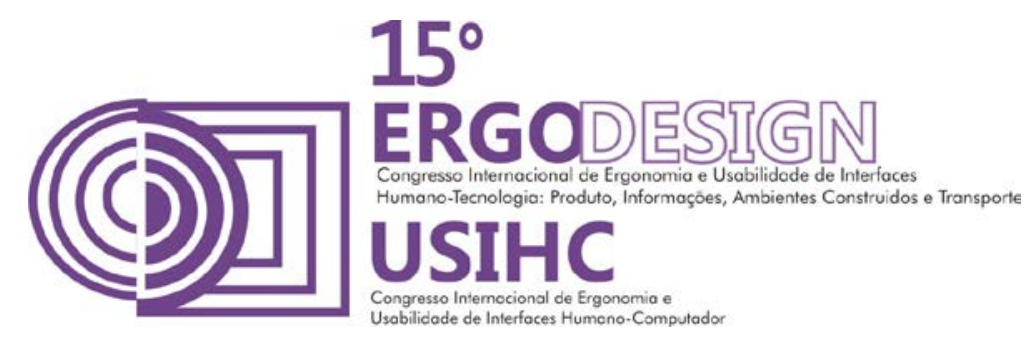

\subsubsection{Modelagem do sistema}

São encontrados cinco elementos: 1) mesa de apoio; 2) cadeira giratória; 3) Suporte de resfriamento; 4) Máquina injetora HAITIAN Modelo MA 3800/2250 e; 5) Peças injetadas (conforme Figura 1). O operador executa suas tarefas entre duas máquinas injetoras, sentado em uma cadeira estofada, sem apoio para os braços e com rodízios.

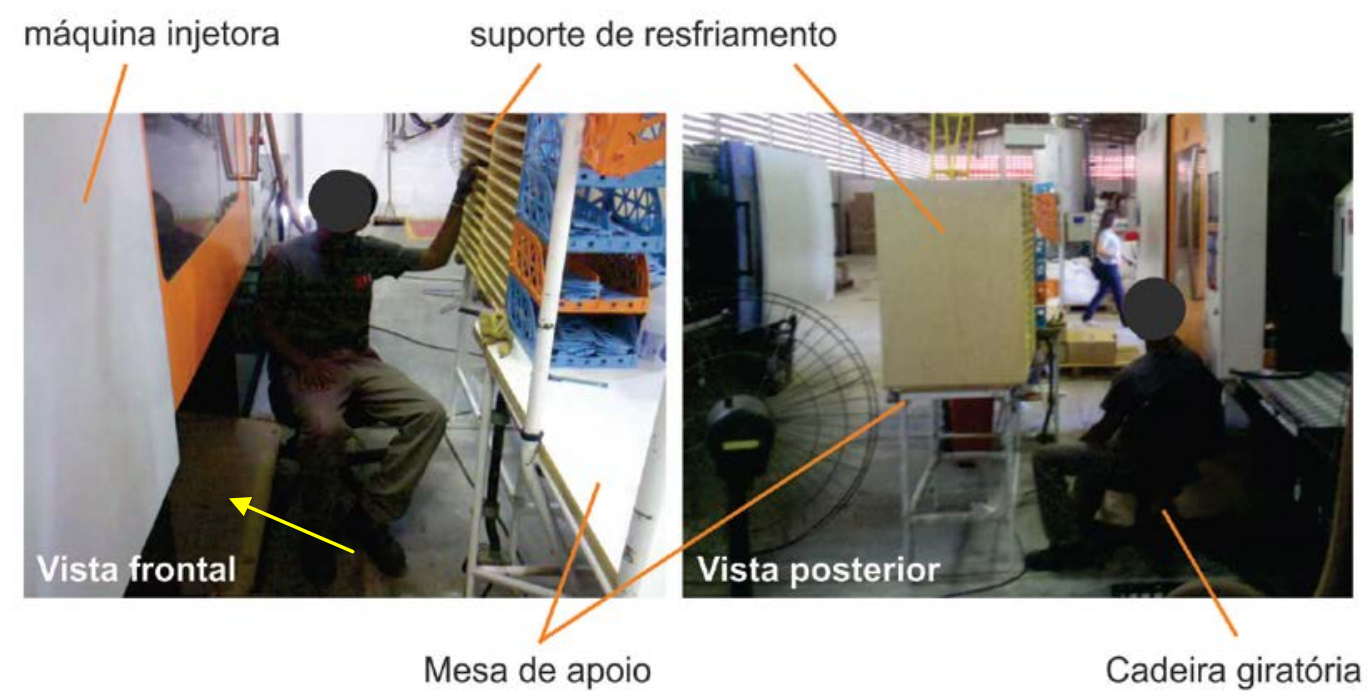

Figura 2. O operário no posto de trabalho

\subsubsection{Caracterização e posição serial do sistema}

- Sistema alvo: posto de trabalho do operador de máquina injetora;

- Ambiente de sistema: que é a linha de produção de displays.

- Meta do sistema alvo: execução de tarefas que finalizem com a fabricação de displays, conforme a ordem de pedido.

- Requisitos: treinamento adequado; espaço suficiente para movimentação; limpeza do posto de trabalho; abastecimentos dos silos; Ordem de Serviço; boas condições do ambiente físico; disponibilidade de ferramentas de manutenção; Molde correto.

- Sistema alimentador: setor de almoxarifado e silos; Os polímeros granulados são as entradas do sistema. As saídas são as peças de displays fabricadas.

- Sistema ulterior: mesa de apoio e posteriormente o setor de embalagem.

- Restrições: falta de material e de energia elétrica. A falta de manutenção preventiva e exigência da demanda. 


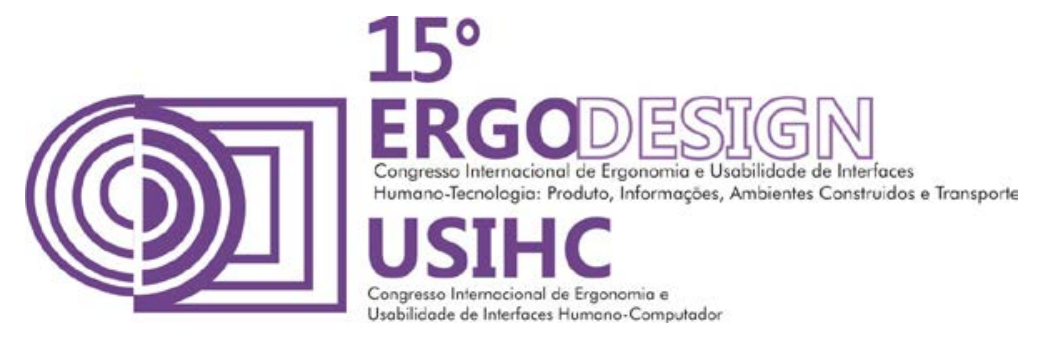

- Resultados despropositados: acidentes e incidentes; displays com defeito de fabricação; refugos; cansaço do operador e fadigas.

\subsubsection{Expansão do sistema}

Segundo Moraes \& Mont'Alvão (2010), um determinado sistema apresenta outros sistema ligados a ele. O posto de trabalho analisado está dentro do supra-sistema denominado "linha de produção de displays". A seguir, os demais sistemas.

- Sistemas paralelos: alimentação de silos; almoxarifado;

- Sistemas seriais: Processamento inicial do polímero (antes da execução da tarefa no posto de trabalho); Processo de embalagem (depois da execução).

- Sistema redundante: as outras três máquinas injetoras.

- Sistemas paralelos: Administração/gerência; Planejamento e Controle de ProduçãoPCP; Vendas; Distribuição.

\subsubsection{Tabela da função informação-ação}

A tabela 1 identifica a informação que é exigida para cada ação e decisão tomada. Buscou-se identificar alguns problemas que podem ocorrer durante a produção dos displays, podendo gerar gargalos que limitem ou atrasem a produção.

Tabela 1. Tabela da função informação-ação

\begin{tabular}{|c|c|c|c|c|c|c|}
\hline \multirow[b]{2}{*}{ FUNÇÃO } & \multicolumn{3}{|c|}{ INFORMAÇÃO } & \multicolumn{3}{|c|}{ AÇÃO } \\
\hline & $\begin{array}{l}\text { Informações } \\
\text { requeridas }\end{array}$ & $\begin{array}{c}\text { Fontes de } \\
\text { informação }\end{array}$ & Dificuldades & Ação & $\begin{array}{c}\text { Objeto da(s) } \\
\text { ação(ões) }\end{array}$ & Dificuldades \\
\hline \multirow{3}{*}{$\begin{array}{l}\text { Operador } \\
\text { de máquina } \\
\text { injetora }\end{array}$} & $\begin{array}{l}\text { Produzir os } \\
\text { displays }\end{array}$ & $\begin{array}{c}\text { Procedimento } \\
\text { operacional } \\
\text { padrão } \\
\end{array}$ & $\begin{array}{l}\text { Mudar molde, } \\
\text { Inserir polímero }\end{array}$ & $\begin{array}{l}\text { Acionar } \\
\text { a máquina } \\
\text { injetora }\end{array}$ & $\begin{array}{c}\text { Botão } \\
\text { Liga/desliga }\end{array}$ & $\begin{array}{l}\text { Gargalo na } \\
\text { produção }\end{array}$ \\
\hline & $\begin{array}{l}\text { Localização } \\
\text { da saída } \\
\text { do display }\end{array}$ & $\begin{array}{l}\text { Visualização do } \\
\text { operador da } \\
\text { máquina }\end{array}$ & $\begin{array}{l}\text { O display pode } \\
\text { ficar preso na } \\
\text { saída da injetora }\end{array}$ & $\begin{array}{l}\text { Desligar a } \\
\text { máquinae } \\
\text { realizar limpeza } \\
\text { da saída }\end{array}$ & $\begin{array}{l}\text { Botão de } \\
\text { emergência. } \\
\text { Porta } \\
\text { móvel frontal }\end{array}$ & $\begin{array}{c}\text { O sistema } \\
\text { travar. } \\
\text { Faltar energia. } \\
\text { A máquina } \\
\text { resfriar }\end{array}$ \\
\hline & $\begin{array}{l}\text { Peças sendo } \\
\text { Mal produzidas }\end{array}$ & $\begin{array}{c}\text { Odor de plástico } \\
\text { fundido/ } \\
\text { queimado }\end{array}$ & $\begin{array}{c}\text { Confundir com o } \\
\text { Odor característico } \\
\text { da conformação }\end{array}$ & $\begin{array}{l}\text { Apertar o } \\
\text { botão de } \\
\text { emergência }\end{array}$ & $\begin{array}{l}\text { O botão de } \\
\text { emergência }\end{array}$ & $\begin{array}{l}\text { Local de difícil } \\
\text { acesso ao botão } \\
\text { de emergência }\end{array}$ \\
\hline
\end{tabular}

\subsubsection{Problematização do Sistema Humano-Tarefa-Máquina}

De acordo com Bunge (1975, p.41) e Moraes \& Mont'Alvão (2010), a apresentação de um problema pode ser dividida em três fases: 1) reconhecimento dos fatos; 2) descoberta do 


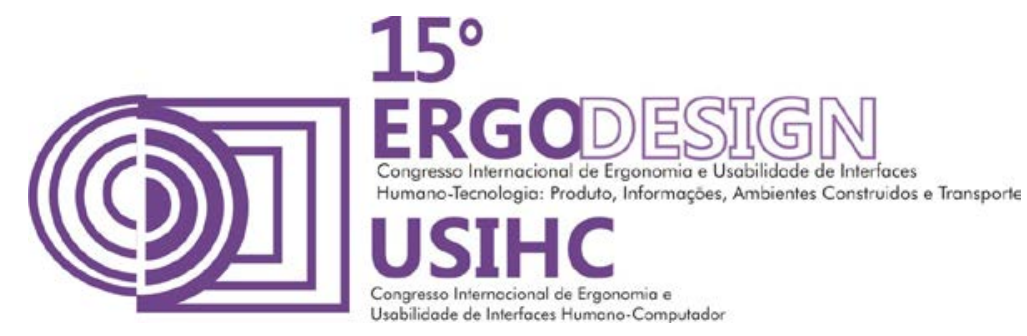

problema; 3) formulação do problema. No presente trabalho, serão citados os problemas encontrados, devidamente categorizados, o que torna mais fácil sua compreensão e solução.

- Problemas informacionais/visuais: deficiência no campo de visão do operário na identificação de informações no painel, podendo provocar erros;

- Problemas organizacionais: posicionamento das máquinas causam baixa luminosidade de ventilação;

- Problemas acionais: constrangimentos biomecânicos em algumas etapas, tais como execução de movimentos de força e torção;

- Problemas operacionais: atividades monótonas e repetitivas;

- Problemas psicossociais: ausência de vivência, descanso ou lazer para os funcionários;

- Problemas acionários: Ausência de sinalização de emergência;

- Problemas espaciais: falta de otimização de iluminação; ausência de isolamento acústico;

- Problemas interfaciais: Permanência na posição sentada, alternância de postura, inclinação da coluna forcando a lombar, rotação do tronco, inclinação da cabeça forçando a cervical. A Foto 1 mostra alguns detalhes de movimentos e postura.

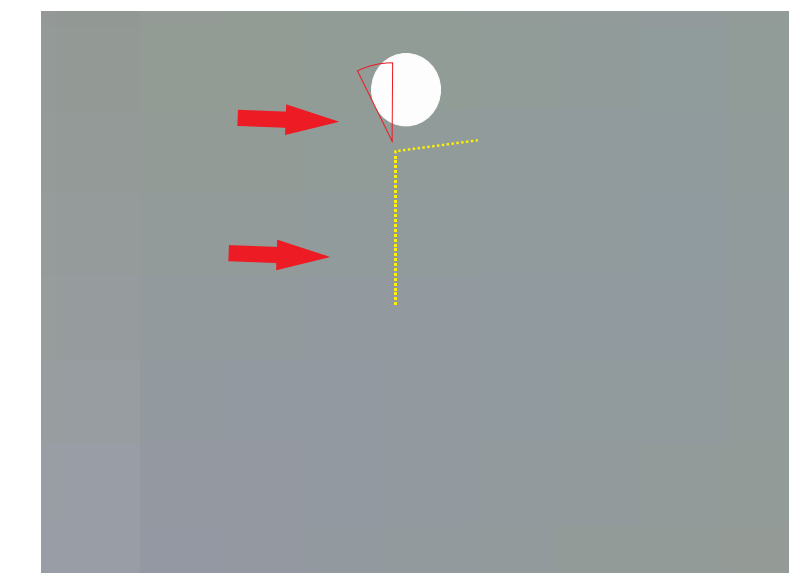

Foto 1. Postura e movimentos inadequados na execução da tarefa

\subsubsection{Parecer ergonômico sobre o Sistema Humano-Tarefa-Máquina-SHTM}

O parecer ergonômico, de acordo com Moraes \& Mont'Alvão (2010) corresponde a uma síntese dos problemas que foram encontrados. Trata-se de uma etapa imprescindível para a Diagnose Ergonômica, e que possibilitará a construção de instrumentos mais consistentes e confiáveis.

A tabela G.U.T. corresponde a hierarquização dos problemas, priorizando-os alguns critérios, tais como gravidade do problema, a urgência de se eliminar o referido problema e a tendência de crescimento do mesmo. De acordo com as análises, o resultado foi o seguinte: 


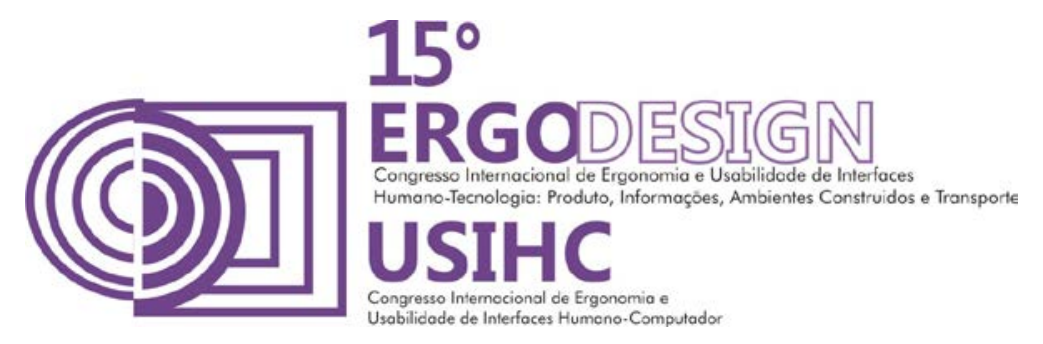

Tabela 2. Tabela de pontuação da técnica G.U.T.

\begin{tabular}{|c|c|c|c|}
\hline Pontos & Problemas & Pontos & Problemas \\
\hline 125 & Má sinalização & 27 & Má visualização do display \\
\hline 48 & Flexão/extensão tronco & 27 & Retirar rebarba \\
\hline 48 & Inclinação do tronco & 27 & Torcer a peça \\
\hline 48 & Flexão/extensão braço & 27 & Atividade repetitiva \\
\hline 36 & Postura sentada & & \\
\hline
\end{tabular}

\subsubsection{Predições}

São apresentadas as interpretações para as causas dos problemas que serão minuciosamente investigadas durante a diagnose ergonômica. A falta de sinalização de emergência é observada em toda a empresa. Por isso a pontuação máxima da tabela G.U.T. foi nesse aspecto. Boa parte dos problemas identificados tem haver necessariamente com postura e manuseio do produto pós-fabricação. Alguns fatores de conforto ambiental são citados como deficientes, como a iluminação direcional e a iluminação geral da empresa. As questões voltadas ao descanso, descontração e lazer não são levadas em consideração na indústria.

\subsection{Diagnose Ergonômica}

Nesta etapa busca-se o aprofundamento dos problemas priorizados. De acordo com Soares (2013, p. 02) nesta etapa ocorrem as observações sistemáticas das atividades relacionadas a tarefa, os registros de comportamento do operador numa situação real. Abrange a análise macroergonômica, que "trata dos níveis hierárquicos, da comunicação da empresa, da participação dos trabalhadores e da organização do trabalho" (MORAES \& MONT'ALVÃO, 2010). Também compreende a análise comportamental da tarefa.

\subsubsection{Análise da ambiência da tarefa}

Esta análise refere-se ao levantamento de dados sobre o ambiente no que tange o conforto ambiental. Utilizando instrumentos e técnicas específicas para medição de iluminação, ruído, temperatura e vibração, é possível identificar fatores que podem influenciar de modo positivo ou negativo o ambiente de trabalho onde está instalado o posto de trabalho.

- Análise global do ambiente: ampla área interna; piso de blocos de cimento; paredes em alvenaria; pé direito alto; sem problemas de fluxo e movimentação.

- Identificação da configuração ambiental: piso regular e acessível; layout atende as expectativas da produção; as medições lumínicas que atendem ao posto de trabalho indicaram insuficiência na iluminação; As medidas acústicas não atendem as recomendações de conforto; A ventilação no entorno do posto de trabalho são adequadas. 


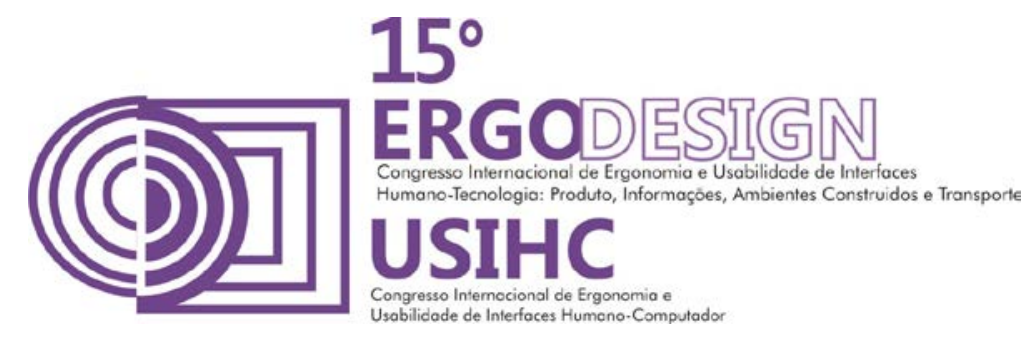

- Avaliação do ambiente em uso: A distância das máquinas e equipamentos permite um fluxo adequado e eficiente.

\subsubsection{Discriminação da tarefa}

Segundo Moraes \& Mont'Alvão (2010), a discriminação da tarefa descreve todas as atividades envolvidas para sua execução e os meios que são utilizados para sua realização (figura 3).

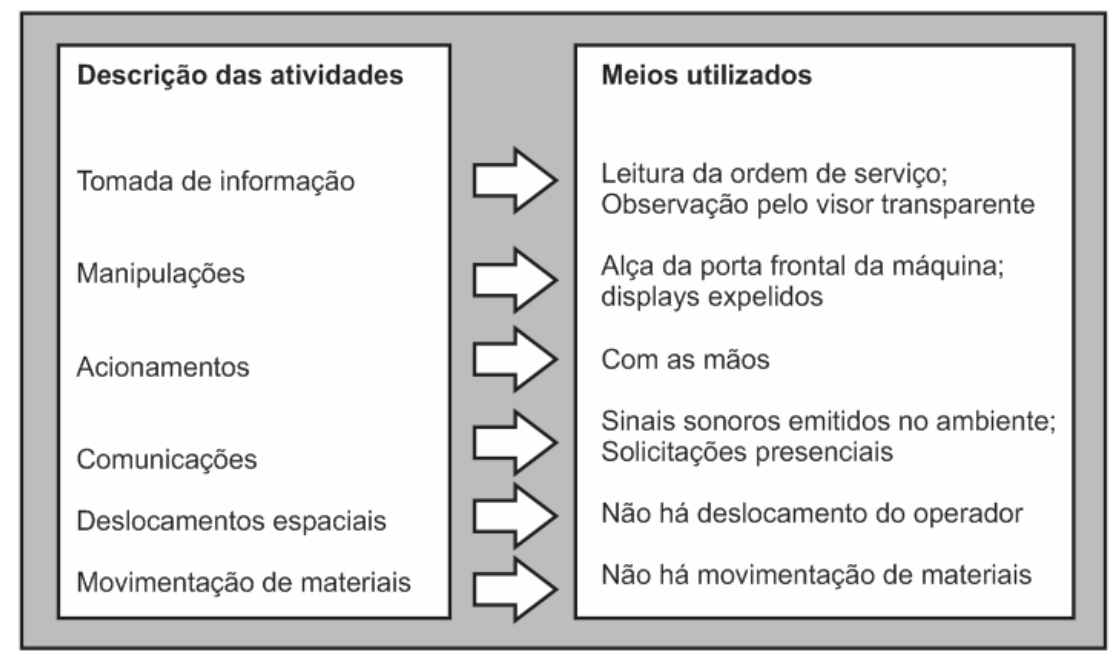

Figura 3. Discriminação da tarefa

\subsubsection{Perfil e voz dos operadores}

Esta fase da pesquisa inclui a análise do conteúdo das respostas obtidas através da aplicação do questionário quanti-qualitativo. Participaram dez operadores, que trabalham no setor de transformação, utilizando as máquinas injetoras. A seguir algumas das respostas obtidas.

- $70 \%$ dos funcionários são homens; $60 \%$ são casados; $30 \%$ possui veículo próprio; $50 \%$ estão com seu peso corporal considerado ideal conforme o IMC; $70 \%$ dos funcionários estão empregados na indústria há menos de 12 anos; 40\% gastam menos de 30 minutos no trajeto entre sua casa e o trabalho;

- A maior queixa quanto ao conforto ambiental está na temperatura no local; Quanto às características do posto de trabalho e do mobiliário, a maior queixa está na bancada ou mesa de apoio, considerado alto. Já a maior satisfação está no espaço disponível para execução das tarefas.

\subsubsection{Avaliação de custo postural do trabalho}

A ergonomia tem um enfoque sistêmico focado no ser humano. Segundo Soares (2013, p.06) um trabalhador, dependendo da atividade que exerce, pode assumir centenas de posturas diferentes e cada uma delas aciona um conjunto diferente de músculos. Faz-se necessária a 


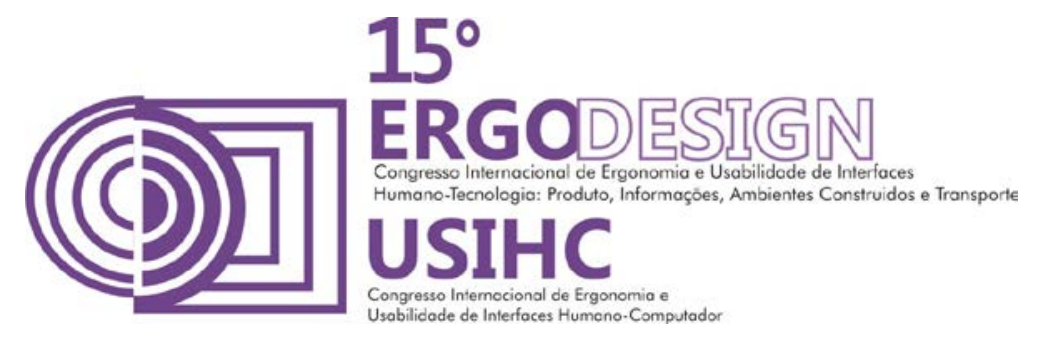

utilização de técnicas sistemáticas para obtenção do registro e da análise da postura. Foram utilizadas algumas ferramentas:

- Checklist de Couto: as perguntas se referiam a sobrecarga física, a postura no trabalho, a repetitividade e organização do trabalho, a força executada com as mãos, ao posto de trabalho e esforço estático e as ferramentas de trabalho. O somatório final indicou 12 pontos, que pelo critério de interpretação indica que o fator biomecânico do clico é significativo, indicando uma situação de risco.

- Método Suzanne Rodgers: Este método consiste numa avaliação que contempla os esforços exigidos em regiões distintas do corpo, preliminarmente definidas. Este método apontou na análise do resultado que há uma necessidade média de mudanças no posto de trabalho, pois as partes do corpo que exercem esforço durante a tarefa são exigidas de modo leve a moderado.

- Registro de comportamento do operador: Foi observada a postura do operador durante o ciclo de execução da tarefa por um período de 20 minutos, divididos em duas etapas de 10 minutos: O operador permaneceu com a coluna ereta em 55,3\% do tempo. As demais posturas tiveram a seguinte porcentagem: coluna inclinada em 18,4\%; curvada em 10,5\%; e rotação do tronco em 15,8\%.

- Mapa de regiões corporais: O "Diagrama de Corlett" foi utilizado, pois ele avalia o desconforto corporal, facilitando a descoberta de áreas de dor nos trabalhadores, mapeando o desenvolvimento do desconforto percebido. As maiores queixas ocorrem na região lombar das costas e na região média, entre a lombar e a cervical.

Com as informações e os resultados obtidos através das técnicas de intervenção ergonomizadora aplicadas durante a análise da tarefa e do posto de trabalho, foram geradas recomendações que exigiram modificações em algumas etapas da produção. Diante do exposto, é importante concentrar as melhorias do posto de trabalho focando na postura do trabalhador e nas pegas e manejos. A próxima etapa evidenciará as modificações através da projetação ergonômica.

\subsection{Projetação ergonômica}

Esta parte da abordagem do Sistema-Humano-Tarefa-Máquina também é desenvolvida de maneira sistêmica e sistemática, trazendo consigo alternativa(s) para a solução dos problemas relatados ao longo da pesquisa, em especial aquelas destacadas na diagnose ergonômica.

Segundo Pasqualini et al (2010, p.58) alguns objetivos devem ser atingidos em um projeto ergonômico, independentemente de sua abrangência e enfoque:

- Adequar o posto de trabalho aos limites e capacidades física, psicológica e mental do indivíduo;

- Otimização das condições de trabalho buscando adquirir produtividade, qualidade e eficiência;

- Proporcionar condições para a participação dos colaboradores; 


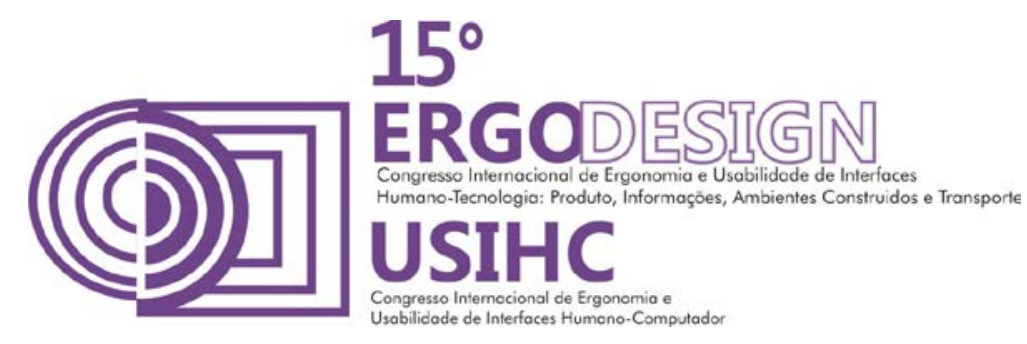

- Proporcionar qualidade de vida no trabalho, bem estar, segurança, satisfação e conforto;

- Buscar a prevenção de acidentes, evitar o erro humano e as doenças ocupacionais.

Apesar de terem sido geradas sugestões de melhorias baseadas nos problemas identificados por categorias, será citado a projetação que otimiza o processo de produção e modifica a postura do trabalhador. É importante mencionar que nem sempre é possível adotar todas as medidas necessárias pois os custos referentes ao tempo de paralização das máquinas, de movimentação das mesmas, de testes com os operadores para verificação da eficiência das melhorias, são limitações relevantes e devem ser minuciosamente estudados.

\subsubsection{Sugestão de novo layout e equipamentos}

Uma sugestão que pode auxiliar uma parte dos problemas identificados é a adoção de esteiras modulares junto às máquinas injetoras. A instalação desse equipamento permitiria uma redução na movimentação de postura dos operários, alternância da postura em pé/sentado e permitiria uma alteração no layout do setor de produção que possibilitaria uma maior incidência de luz e consequentemente de ventilação. A Figura 4 exibe um modelo digital em terceira dimensão (3D) da solução recomendada, mostrando a situação anterior e após as mudanças.
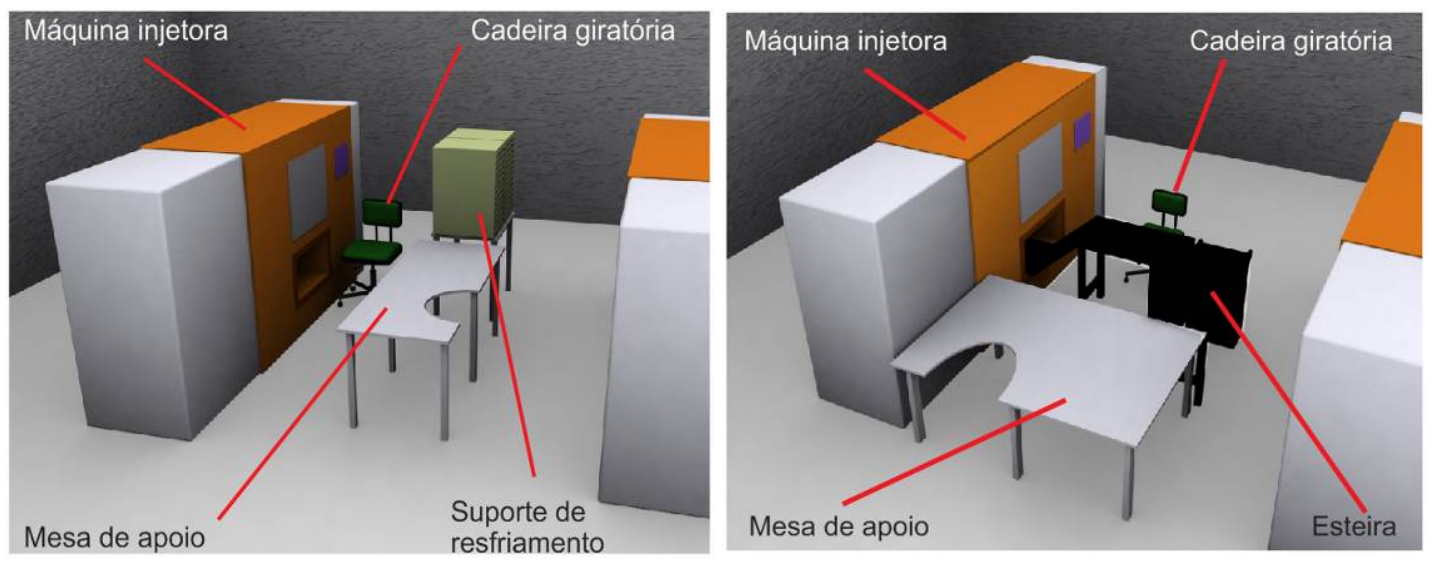

Figura 4. O layout anterior (esquerda) e o novo layout (direita)

\section{CONCLUSÕES}

Este estudo teve o intuito não apenas de apresentar soluções para problemas do cotidiano de uma indústria, mas de despertar nos pesquisadores uma visão global e sistêmica do ambiente de trabalho, enxergando com um olhar ergonômico o ambiente, o local e o posto de trabalho.

A produtividade, eficiência, alcance de metas e motivação não são obtidos apenas com investimentos em tecnologia e treinamento, mas também enxergando o trabalhador não somente como parte do processo, mas como um ser humano, com suas qualidades e 


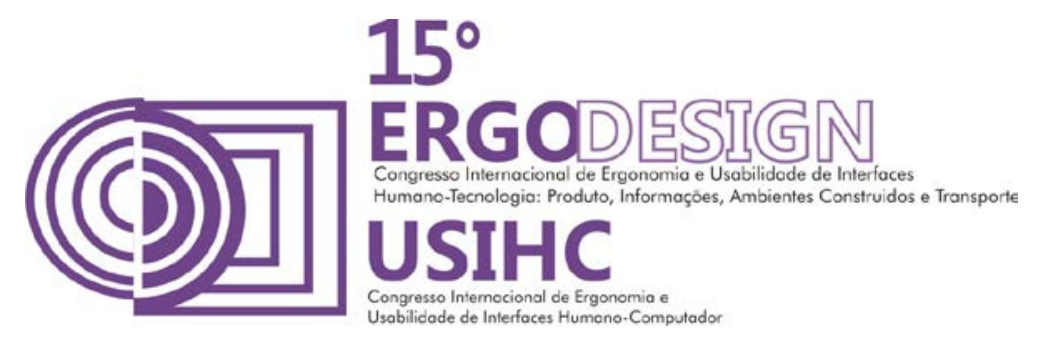

limitações. E a ergonomia mantem esse foco no ser humano. Os objetivos desse trabalho foram alcançados no que tange a realização de uma apreciação ergonômica e geração de melhorias.

\section{REFERÊNCIAS BIBLIOGRÁFICAS}

BUNGE, M. La ciencia: su método y su filosofia. Buenos Aires, Siglo Veinte, 1975.

COUTO, H. A. Como instituir a ergonomia na empresa: a prática dos comitês de ergonomia. Belo Horizonte: ERGO editora, 2011.

GIL, A. C. Métodos e Técnicas de Pesquisa Social. São Paulo: Atlas, 2005.

GUIMARÃES, L. B. de M. Organização do trabalho: Ergonomia de Processo. VIII Curso de Especialização em Ergonomia. Recife: UFPE, julho de 2013. 36 p. Notas de Aula.

IIDA, I. Ergonomia: projeto e produção. 2ed. São Paulo: Edgard Blücher, 2005.

LAKATOS, E. M. Fundamentos de Metodologia Científica. /Marina de Andrade Marconi, Eva Maria Lakatos. 5ed. São Paulo: Atlas, 2003.

LEPLAT, J. e CUNY, X. Introdução à psicologia do trabalho. Lisboa: Fundação Calouste Gulbenkian, 1977.

LUCENA, F. de O.; LUCENA, K. K. C.; CHAVES, R. M.; AMORIM, R. M. M. Estratégia da Produção: Um estudo multicaso nas indústrias de Campina Grande. In: Simpósio de Engenharia de Produção da Região Nordeste, 2, 2007, Campina Grande. Anais... Campina Grande: UFCG, 2007. CD-ROM.

MORAES, A. de; MONT'ALVÃO, C. Ergonomia: conceitos e aplicações. 4 ed. Rio de Janeiro: 2AB, 2010;.

MUCHINSKY, P. M. Psicologia organizacional. São Paulo: Editora Thomson Pioneira, 2004.

PASQUALINI, F.; LOPES, A. O.; SIEDENBERG, D. Gestão da Produção. Coleção Educação à Distância, 100p. Série Livro-Texto. Ijuí: Editora Unijuí, 2010.

SOARES, M. M. Ergonomia: princípios, métodos e técnicas. Universidade Federal de Pernambuco: Recife, 2009. II Curso de Extensão à Distância em Ergonomia: Princípios, Métodos e Técnicas. 01 set. 2009 a 31 out. 2009. Notas de aula.

SOARES, M. M. Metodologia de Intervenção Ergonomizadora: Diagnose Ergonômica. VIII Curso de Especialização em Ergonomia. Recife: UFPE, novembro de 2013. 59 p. Notas de Aula. 